\title{
MATHEMATICAL MODEL \\ TO PREDICT INSPIRED OXYGEN CONCENTRATION: DESCRIPTION AND VALIDATION
}

\author{
H.R. Wexler, H. Levy, J.D. Cooper, and A. Aberman
}

IN THE MANAGEMENT of patients with respiratory failure, it is important to know and control the inspired oxygen concentration $\left(\mathrm{F}_{\mathrm{I}_{2}}\right)$ for two reasons. First, unnecessarily high $\mathrm{F}_{\mathrm{I}_{2}}$ must be avoided, if possible, to prevent pulmonary oxygen toxicity. ${ }^{2}$ Second, knowledge of the $\mathrm{F}_{\mathrm{O}_{2}}$ is necessary to calculate the alveolar $\mathrm{P}_{\mathrm{O}_{2}}\left(\mathrm{~Pa}_{\mathrm{O}_{2}}\right)$ using the alveolar gas equation and thus the alveolar arterial oxygen gradient, which is an important measure of the extent of pulmonary disease.

When the patient is breathing through non-rebreathing closed systems, such as a tracheal tube connected to a ventilator, the $\mathrm{FI}_{\mathrm{O}_{2}}$ is the administered oxygen concentration. However, with non-occlusive face masks and other open systems, the $\mathrm{FI}_{\mathrm{C}_{2}}$ is determined not only by the oxygen concentration administered but by the patient's tidal volume, respiratory frequency and inspiratory fraction (that portion of the respiratory cycle devoted to inspiration) as well as by physical characteristics of the masks. Therefore, to know the $\mathrm{Fr}_{\mathrm{O}_{2}}$ in these patients, the intratracheal oxygen concentration must be directly measured. In most patients it is impractical to perform such a procedure repeatedly.

This study describes a mathematical model which can be used to calculate the

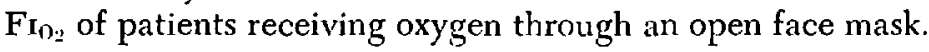

\section{Methods}

\section{A. The Mathematical Model (Figure 1)}

Inspiratory flow was assumed to be a sine wave..$^{3,4}$ The inspiratory time can be measured directly or calculated from the respiratory frequency and inspiratory fraction. Thus the area under the respiratory flow curve is the tidal volume. The delivered oxygen is represented by the horizontal line intercepting the flow axis at the appropriate value. This model assumes that as long as the patient's inspiratory flow does not exceed the delivered oxygen flow, the instantaneous inspiratory volume is comprised solely of the delivered gas. When the patient's inspiratory flow exceeds the delivered oxygen flow, then the instantaneous inspiratory volume is made up of two components; first, the delivered gas, and secondly room air. The volume of room air is the difference between the patient's instantaneous inspiratory volume and the delivered gas volume. Thus the tidal volume

From the Department of Medicine, Mount Sinai Hospital and the Departments of Surgery and Anaesthesia, of the Toronto General Hospital and the University of Toronto.

Reprint requests to: Dr. A. Aberman, Suite 431, Mount Sinai Hospital, 600 University Ave., Toronto, Ontario. 


\section{$\mathrm{F}_{1} \mathrm{O}_{2}=\frac{\text { Volume air } \times \cdot 21+\text { Volume } \mathrm{O}_{2}}{\text { Tidal Volume }}$}

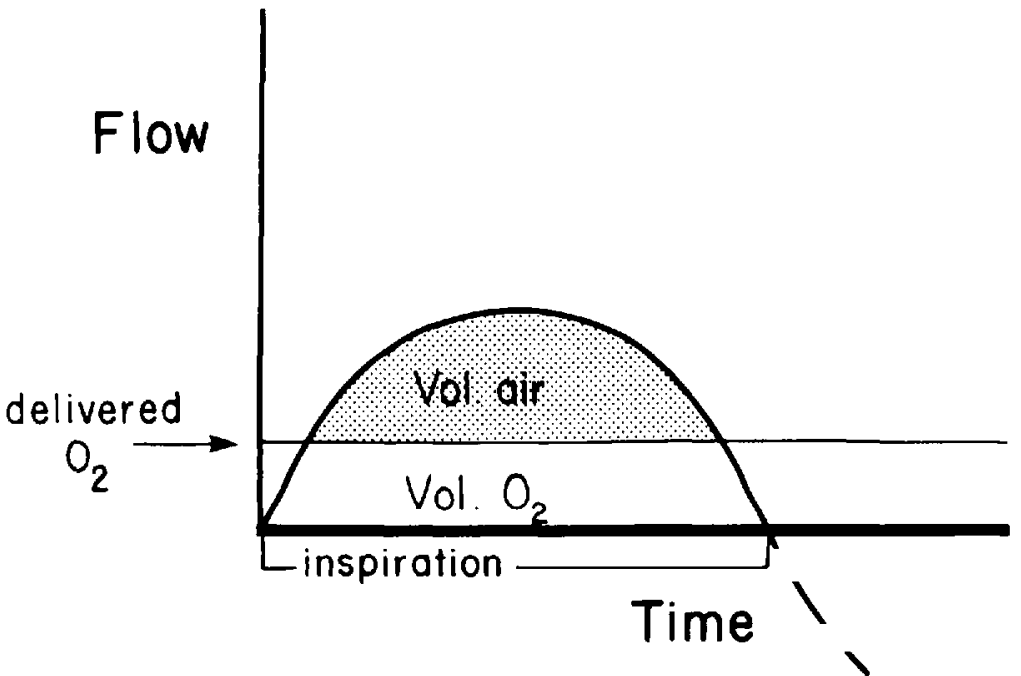

FIGURE 1. Graphic representation of mathematical model. Sine wave represents inspiratory flow. Horizontal line represents flow rate of oxygen to the mask.

is composed of two volumes, these being the volume of delivered gas and the volume of inspired room air.

These two volumes can be calculated if the delivered oxygen flow, the patient's tidal volume, respiratory frequency and inspiratory fraction using uncomplicated integration techniques are known. Using these two volumes and assuming delivery of 100 per cent oxygen $\mathrm{F}_{\mathrm{O}_{2}}$ can then be calculated with the following formula.

$$
\mathrm{FI}_{\mathrm{O}_{2}}=\frac{1 \times \text { volume } \mathrm{O}_{2}+0.21 \times \text { volume air }}{\text { Tidal volume }}
$$

An adjustment can be made for lower delivered oxygen concentrations.

The above model makes two important assumptions related to the face mask system. First, the patient only gets gas delivered from the instantaneous oxygen flow and there is no reservoir volume in the mask. If there was such a reservoir volume in the mask, it would replace an equal volume of room air (Figure 2) and thus increase the $\mathrm{F}_{\mathrm{I}_{2} \text {. }}$. The model can accordingly be modified to allow for any such reservoir volume.

The second assumption is that the entire delivered gas flow is available to satisfy the patient's inspiratory requirements. If this were not true, then the effective delivered gas flow would be reduced by that amount of gas flow not available to the patient. The model can be modified to allow for any effective delivered gas flow (Figure 3). 


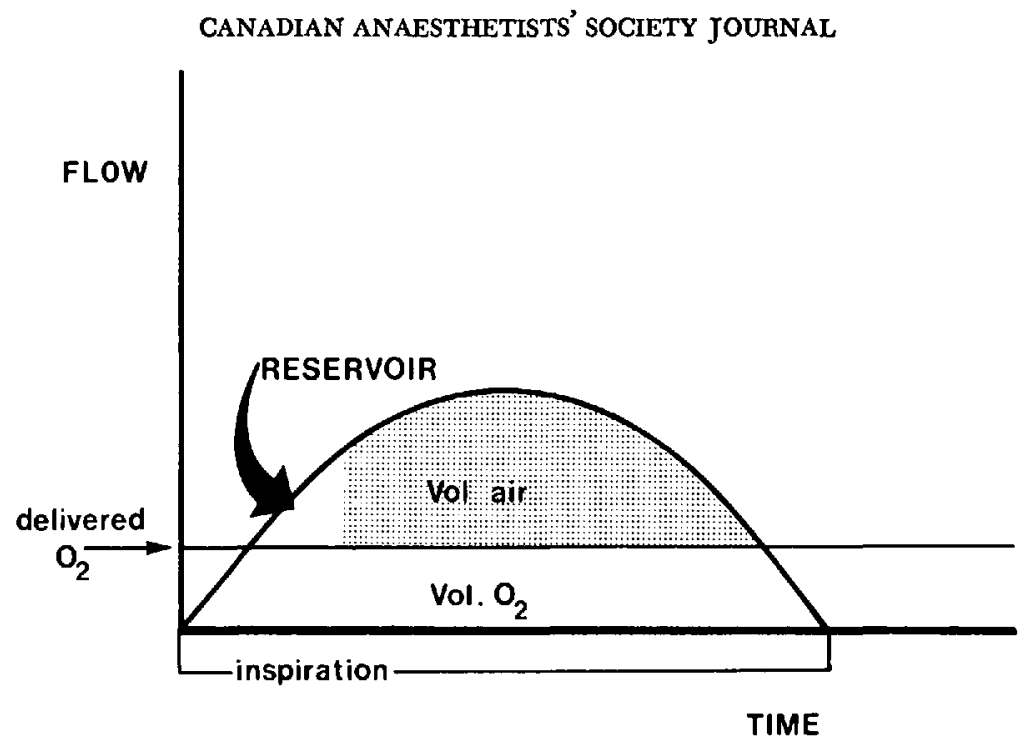

Figune 2. Graphic representation of mathematical model assuming a reservoir volume in mask. Lines as in Figure 1.

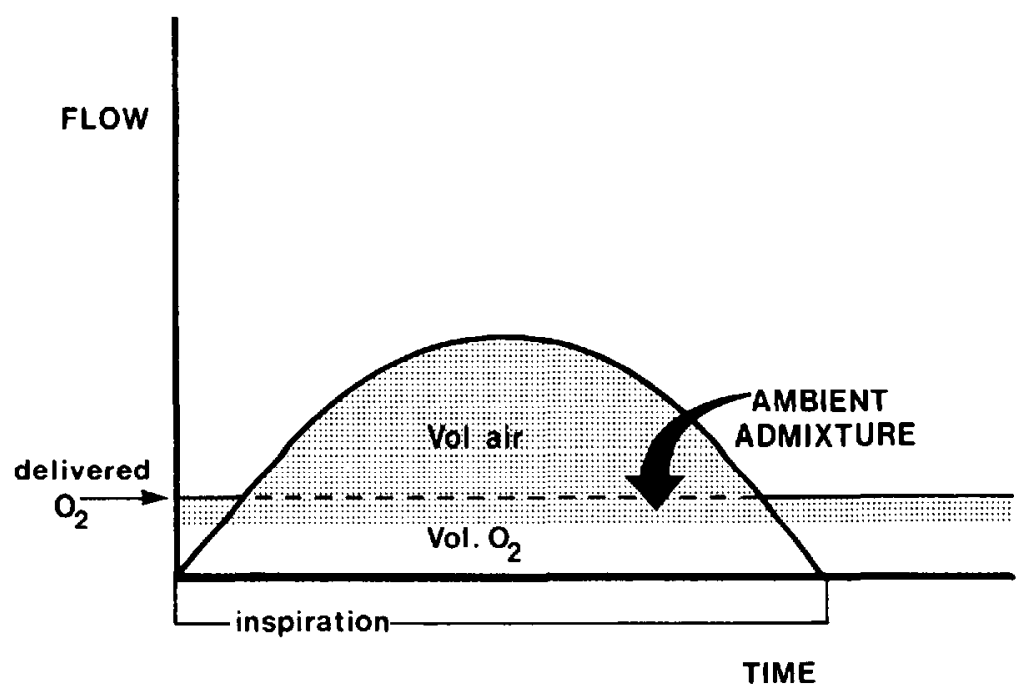

Figure 3. Graphic representation of mathematical model assuming ambient admixture of room air. Line as in Figure 1.

\section{B. Mechanical Analogue (Figure 4)}

We constructed a mechanical analogue to test the mathematical model. A sine wave pump (Harvard Model \#614) was used to simulate the chest wall and lungs. It was attached by the "trachea" (an appropriately sized metal tube) to the "mouth" (a hole in the cardboard backing) breathing through a mask. One hundred per cent oxygen was delivered to the mask through a Puritan Nebulizer, using a calibrated flow meter. A \#19 catheter was inserted through a side port into the "trachea" to sample the inspiratory gas. The percent oxygen in these 


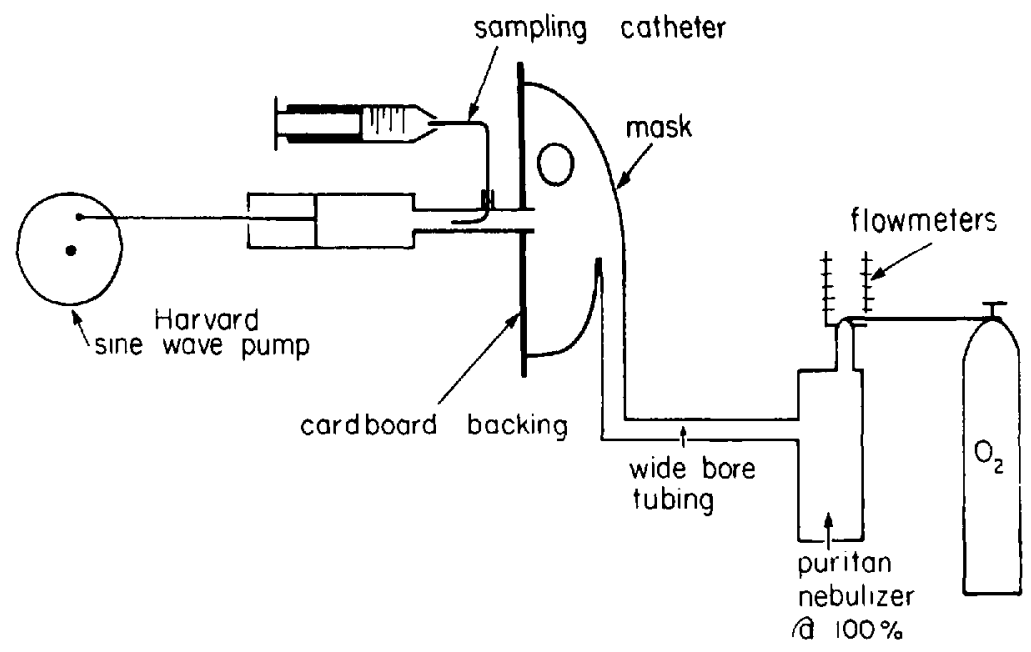

Figure 4. Mechanical analogue of mathematical model. See text.

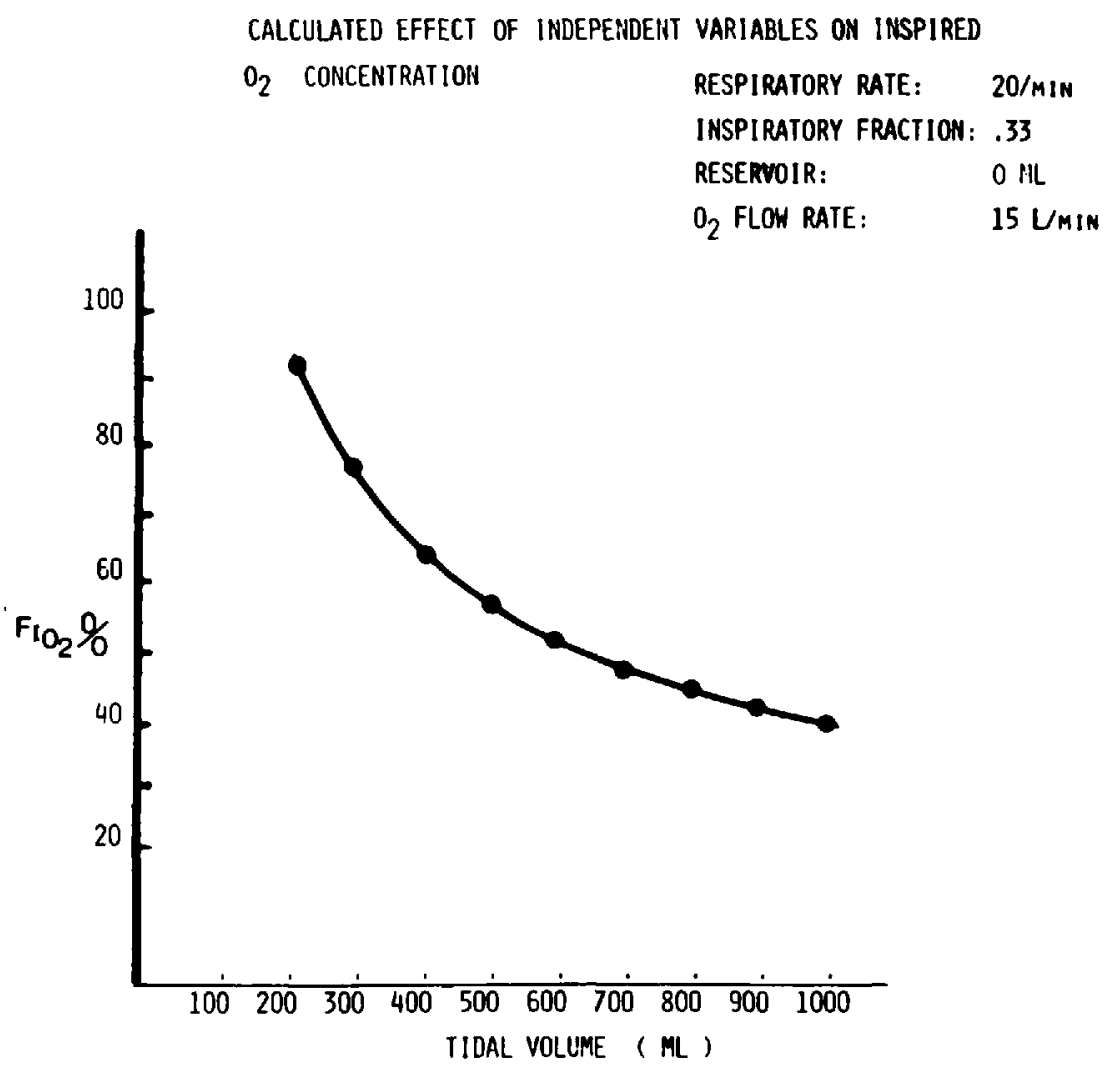

Ficure 5. Effect of Tidal Volume on $\mathrm{FI}_{\mathrm{O}_{2}}$. Respiratory rate, inspiratory fraction, reservoir 


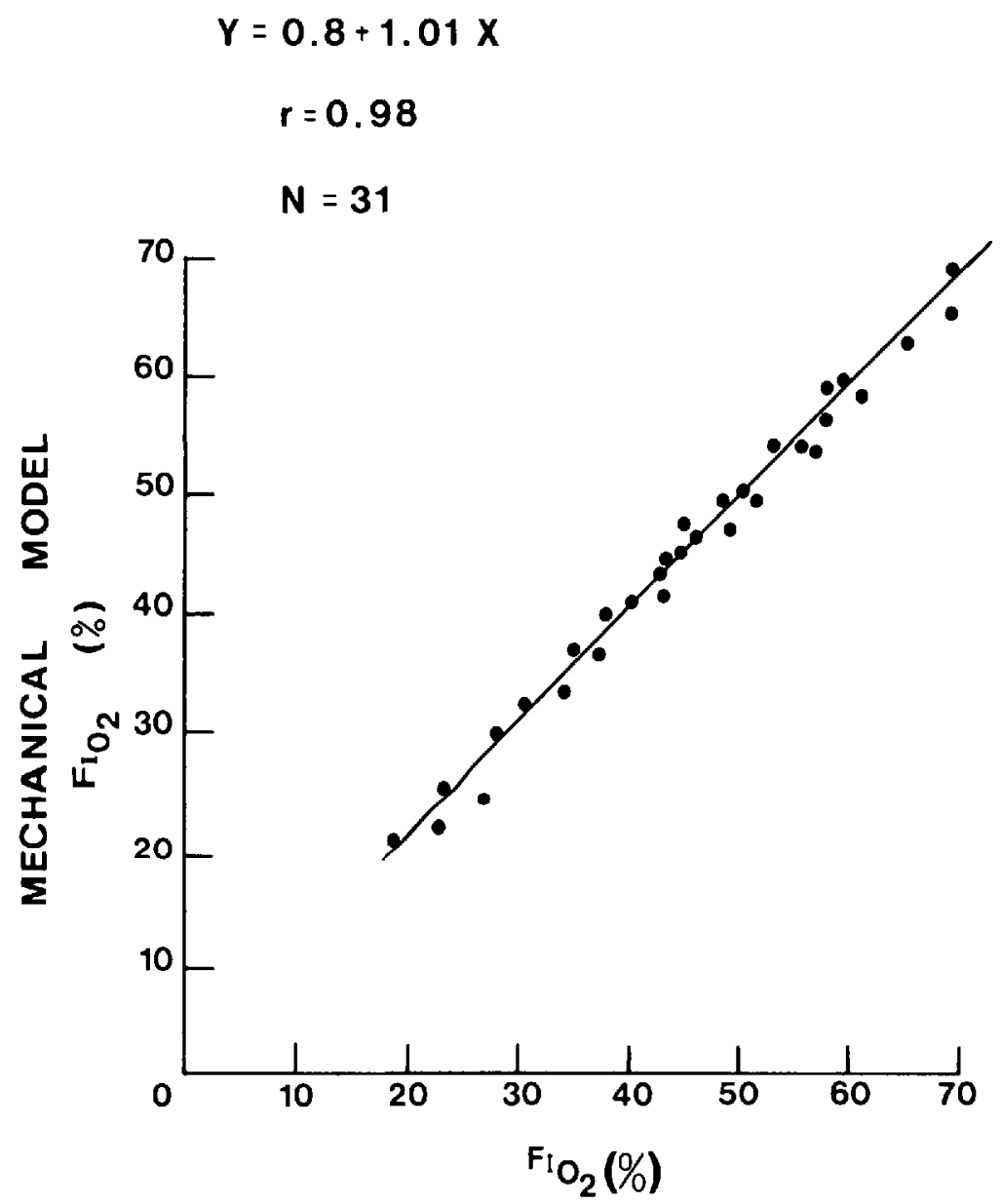

\section{MATHEMATICAL MODEL}

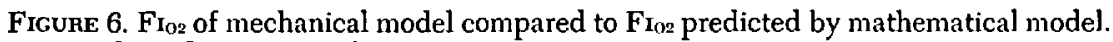
volume and $\mathrm{O}_{2}$ flow rate are kept constant.

aspirated samples was measured in an oxygen analyzer (Beckman OM-11). The $\mathrm{FI}_{\mathrm{O}_{2}}$ was measured directly and calculated by using the mathematical model as "tidal volume," "inspiratory time" and oxygen flow rates were independently varied.

\section{Results}

Using a computer program based on the mathematical model described (see appendix) we were able to study the effect on the $\mathrm{F}_{\mathrm{O}_{2}}$ of varying each of the parameters independently. Figure 5 illustrates the effect on calculated $\mathrm{F}_{\mathrm{O}_{2}}$ of varying the tidal volume, while keeping the remaining parameters constant.

We compared the $\mathrm{FI}_{\mathrm{O}_{2}}$ calculated with the mathematical model to the $\mathrm{FI}_{\mathrm{O}_{2}}$ measured in the "trachea" of the mechanical model (Figure 6). The delivered oxygen flow rates used were 4,8 and $12 \mathrm{l} / \mathrm{min}$. For the calculated $\mathrm{F}_{\mathrm{O}_{2}}$, a reservoir of 0 cc's were assumed at $4 \mathrm{l} / \mathrm{min}, 25 \mathrm{cc}$ 's at $8 \mathrm{l} / \mathrm{min}$ and $50 \mathrm{cc}$ 's at $12 \mathrm{l} / \mathrm{min}$. 
Discussions

The mathematical model used to calculate $\mathrm{F}_{\mathrm{O}_{2}}$ from tidal volume, frequency, inspiratory fraction and delivered oxygen flow rate depends on the validity of three assumptions. First, it is assumed that inspiration is a sine wave from 0 to 180 degrees. Previous studies have demonstrated that this is a reasonable assumption. ${ }^{3,4}$ Secondly, the original model assumed that there was no reservoir volume in the face mask. However, it was simple to modify the model to allow for any assumed reservoir. The model originally assumed, also, that all the delivered gas flow was available to the patient and that room air was inspired to make up the difference between patient's need and gas flow only when the patient inspiratory flow rate exceeded the delivered gas flow. In fact, if all the delivered gas flow is not available to the patient, then the model can be adjusted to use the effective reduced gas flow for the calculations.

With the computer program based on the mathematical model we demonstrated that tidal volume, frequency and inspiratory fraction as well as delivered gas flow each affect the $\mathrm{F}_{\mathrm{O}_{2}}$. The effect of changes in tidal volume on $\mathrm{F}_{\mathrm{I}_{2}}$ is especially important to the patient in whom high oxygen concentration suppresses ventilation. In such patients if the initial $\mathrm{FI}_{\mathrm{O}_{2}}$ causes a decrease in inspiratory rate and tidal volume, then the $\mathrm{F}_{\mathrm{I}_{2}}$ will increase. This of course sets up a positive feedback loop which could only end in severe respiratory depression, and supports the practice of using controlled low concentration oxygen in these patients.

There was excellent agreement between the mechanical model and the mathematical prediction. As the flow rate of oxygen into the model increased, there was an increase of reservoir effect in the mask. This is expected since during "expiration" the mask fills up with a mixture of expired and delivered gas.

We believe that this model will be very useful in predicting the $\mathrm{F}_{\mathrm{O}_{2}}$ on patients receiving oxygen by face mask.

\section{APPENDIX}

FORTRAN Program to calculate $\mathrm{F}_{\mathrm{I}_{\mathrm{O}_{2}}}$ (OXCON) from delivered flow (FLO), respiratory frequency (FREQ), tidal volume (TIDVO), reservoir (DS) and inspiratory fraction (FRAC).

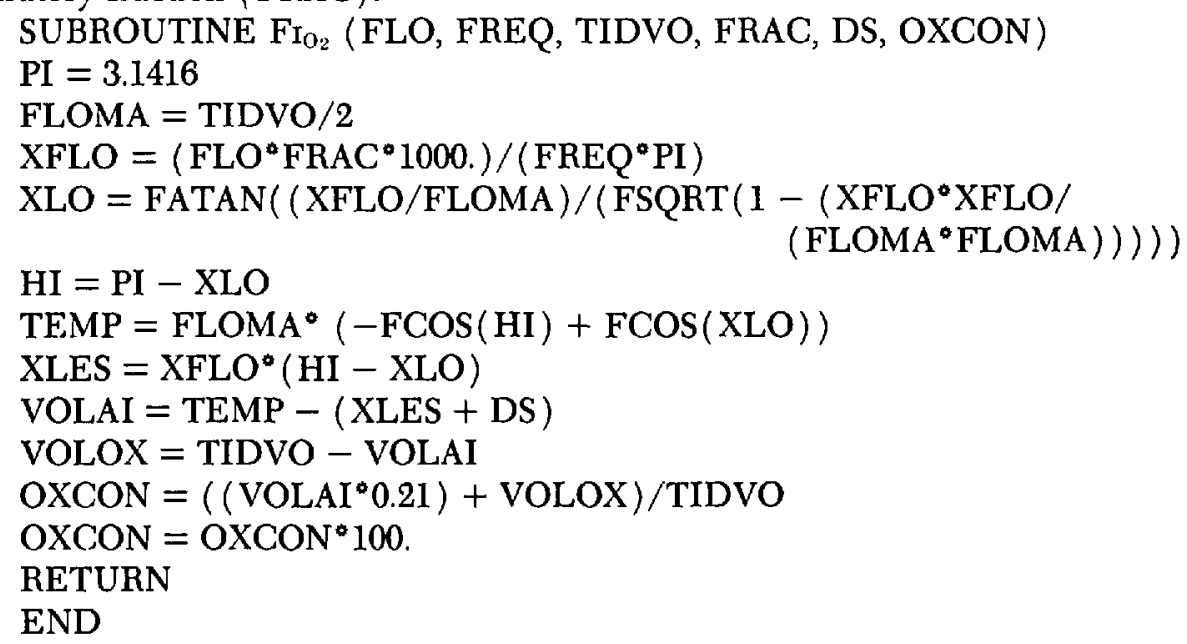




\section{RÉsumé}

Nous avons conçu un modèle mathématique permettant de prédire la $\mathrm{FI}_{\mathrm{O}_{2}}$ dans la trachée des malades recevant de l'oxygène au moyen d'un masque ou d'un autre système ouvert. Ce modèle utilise les paramètres suivants: débit d'oxygène utilisé, volume courant, fréquence respiratoire et durée de l'inspiration.

Un modèle mécanique a été utilisé pour vérifier la précision de cette formule mathématique et l'on a trouvé une excellente corrélation $(r=0.98)$.

\section{REFERENCES}

1. WEST, J.B. Ventilation/blood flow and gas exchange. Oxford, Blackwell, 1970.

2. Morgan, A.P. The pulmonary toxicity of oxygen. Anaesthesiology 29: $570-579$ (1968).

3. Flenley, D.C., Hutchison, D.C.S., \& Donald, K.W. Behaviour of apparatus of oxygen administration. B.M.J. 5365: 1081-1088 (1963).

4. Bethune, D.W. \& Collus, J.M. The evaluation of oxygen masks. Anaesthesia 22: 43-54 (1967). 